\begin{tabular}{|c|c|c|c|}
\hline \multirow{3}{*}{$\begin{array}{r}\text { Case Reports in } \\
\text { Gastroenterology }\end{array}$} & \multirow{2}{*}{\multicolumn{2}{|c|}{ Case Rep Gastroenterol 2015;9:233-240 }} & \multirow[b]{3}{*}{$\begin{array}{l}\text { Karger } \\
\text { Opengaccess }\end{array}$} \\
\hline & & & \\
\hline & $\begin{array}{l}\text { DOI: 10.1159/000437047 } \\
\text { Publisnea onilne: July } 11,2015\end{array}$ & $\begin{array}{l}\text { (c) } 2015 \text { S. Karger AG, Basel } \\
1662-0631 / 15 / 0092-0233 \$ 39.50 / 0 \\
\text { www.karger.com/crg }\end{array}$ & \\
\hline & $\begin{array}{l}\text { This is an Open Access article } \\
\text { Attribution-NonCommercial } 3.0 \\
\text { license), applicable to the online } \\
\text { commercial purposes only. }\end{array}$ & $\begin{array}{l}\text { he terms of the Creative Commo } \\
\text { (CC BY-NC) (www.karger.com/C } \\
\text { le only. Distribution permitted for nc }\end{array}$ & \\
\hline
\end{tabular}

\title{
Pancreatic and Gastric Heterotopia with Associated Submucosal Lipoma Presenting as a 7-cm Obstructive Tumor of the Ileum: Resection with Double Balloon Enteroscopy
}

\author{
Kun Jiang $^{a} \quad$ F. Otis Stephen ${ }^{b} \quad$ Daniel Jeong $^{c} \quad$ Jose M. Pimiento $^{b}$ \\ Departments of anatomic Pathology, ${ }^{b}$ Gastrointestinal Oncology and ${ }^{c}$ Radiology, \\ $H$. Lee Moffitt Cancer Center and Research Institute, Tampa, Fla., USA
}

\section{Key Words}

Gastric heterotopia - Pancreatic heterotopia - Double balloon enteroscopy $\cdot$ Intermittent bowel obstruction

\begin{abstract}
Pancreatic and gastric heterotopias are rare clinical entities which have been identified throughout the entire length of the gastrointestinal tract. Combined gastric and pancreatic heterotopias, although unusual, have been described in the duodenum and jejunum, and in other structures, including Meckel's diverticulum and the ampulla of Vater. We report a novel case of pancreatic and gastric heterotopia with an associated submucosal lipoma in a 38-year-old female with a recent history of rectal cancer and chronic crampy abdominal pain. On computed tomography, a $7-\mathrm{cm}$ luminal polypoid mass extending into the distal ileum was discovered. The mass was successfully resected using retrograde double balloon enteroscopy. We believe this is the first report of all three histological entities co-existing in an obstructive ileal lesion in an adult. It highlights endoscopic resection trough double enteroscopy as a safe alternative to more invasive surgical approaches for this type of lesion.
\end{abstract}


Jiang et al.: Pancreatic and Gastric Heterotopia with Associated Submucosal Lipoma Presenting as a 7-cm Obstructive Tumor of the Ileum

\section{Introduction}

Pancreatic and gastric heterotopias are defined as pancreatic and gastric tissues outside their typical location without vascular or anatomical continuity with the pancreas proper or the stomach [1-3]. The reported incidence of heterotopic pancreas or gastric tissue in the general population is low, ranging from $<1 \%$ to around $13 \%[2,4]$. These are rare clinical entities which have been identified in virtually the entire length of the gastrointestinal system $[2,3]$. However, pancreatic heterotopia is mostly discovered in the stomach, while combined gastric and pancreatic heterotopia is most common in the duodenum and jejunum. Involvement of other organs such as esophagus, terminal ileum, Meckel's diverticulum, colon, ampulla of Vater, gallbladder, spleen, mesentery, liver, bile duct, omentum and urinary bladder are rare but have been previously reported [3].

The clinical significance of pancreatic heterotopia depends on size, location and associated complications. Pancreatic heterotopia often becomes clinically symptomatic when its size reaches $1 \mathrm{~cm}$ in the stomach or duodenum, and it may present with pain, anemia, melena or weight loss [5]. Gastric heterotopias, however, can become clinically significant due to sequelae of acid secretion and/or polyp formation. In the rare cases where pancreatic and gastric heterotopia were reported together, the clinical presentations resulted from a combination of these symptoms [3]. The majority of pancreatic and gastric heterotopias form polypoid or mass-like lesions in the gastrointestinal tract, causing clinical symptoms due to their physical location or mass effects; occasionally, these heterotopias can also present as non-polypoid, irregularly distributed, carpet-like lesions plaquing variable regions of enteric tissues [4].

Although in some cases these entities have been found incidentally, pancreatic and gastric heterotopias have been associated with symptoms such as dyspepsia, abdominal discomfort and pain, gastrointestinal bleeding with or without associated anemia, bowel obstruction and even short bowel syndrome complicated by intestinal malrotation, which was identified in a pediatric patient, with extensive gastric heterotopia involving the duodenum and ileum, leading to congenital short bowel syndrome and malrotation $[2,4]$. Importantly, heterotopias have been described as a leading point for intussusception in the pediatric literature [6], with only a handful of cases reported in the adult population [7, 8]. However, we report a novel case of pancreatic and gastric heterotopia associated with a submucosal lipo$\mathrm{ma}$, identified in a 7-cm distal ileum mass, which was complicated by ileoileal intussusception. We believe that this is the first report of all three histological entities co-existing in an obstructive ileal lesion.

\section{Case Report}

A previously healthy 38-year-old female presented to our institution for evaluation of episodic hematochezia and intermittent crampy lower abdominal pain. Colonoscopy revealed a 2-cm rectal polyp located $5 \mathrm{~cm}$ from the anal verge, and biopsies of this polyp revealed invasive adenocarcinoma. The lesion was completely removed surgically via a transanal approach, which revealed a fully excised T1a adenocarcinoma without evidence of lymphovascular invasion or poorly differentiated/high-grade morphology. Despite surgical resection of the tumor, the patient continued to experience intermittent abdominal pain. A contrast-enhanced computed tomography (CT) scan of the thorax, abdomen and pelvis performed as part of the staging for her rectal tumor was negative for metastatic disease, but incidentally revealed a large polypoid mass in the ileum containing a round nodule sur- 
Jiang et al.: Pancreatic and Gastric Heterotopia with Associated Submucosal Lipoma Presenting as a $7-\mathrm{cm}$ Obstructive Tumor of the Ileum

rounded by adipose tissue (fig. 1). Particularly, this polypoid mass served as a lead point for intussusception. A detailed history revealed progressively worsening symptoms of intermittent nausea, vomiting and crampy abdominal pain since the age of nine, suggesting an intermittent obstructive process that had not been previously identified.

Retrograde double balloon enteroscopy was performed to assess this ileal lesion. The colonic portion of the examination revealed a 3-mm colonic polyp, mid sigmoid diverticulosis and hypervascular nodular mucosa in the rectum at the site of the prior resection, consistent with neo-squamous mucosa. The ileal mucosa was unremarkable; however, a $7.5 \times 2.5 \mathrm{~cm}$ pedunculated polypoid lesion was identified in the ileum, located approximately $135 \mathrm{~cm}$ proximal to the ileocecal valve (fig. $2 \mathrm{a}$ ). There was visual evidence of intermittent ileal-ileal intussusception at the mucosa surrounding the lesion, as suggested by intermittent collapse of the lumen surrounding the lesion as the mass projected distally towards the enteroscope. This lesion was removed endoscopically by snare cautery, after injecting saline submucosally at the base of the mass. Multiple hemoclips were placed at the site of resection for hemostasis and to secure the mucosa at the resection site. There were no procedurerelated complications.

Gross examination of the specimen revealed an elongated mass, $7.5 \mathrm{~cm}$ in length, with mostly smooth mucosal lining (fig. 2b). On specimen dissection, the cut surface of the 'tumor' was yellow, soft, with a 9-mm pink to white, relatively rubbery area in the central portion. Microscopic examination revealed diffuse submucosal circular adipose tissue occupying $>80 \%$ of the lesion, histologically consistent with benign lipoma (fig. 3). Surrounded by the lipoma, the central pink-white area contained pancreatic acini ducts and islets of Langerhans (fig. 3) with no architectural or cytological atypia or dysplastic features (fig. 4). Closer microscopic examination of the surface mucosa revealed a microscopic focus of gastric fundic type epithelium hiding within enteric mucosa without atypia or dysplasia (fig. 4). These findings of abnormally located, ectopic benign pancreatic and gastric tissue were morphologically consistent with co-existing pancreatic and gastric heterotopias residing within a submucosal lipoma. No dysplasia or malignancy was identified. Follow-up of the patient 6 months after resection revealed complete resolution of her obstructive symptoms and subsequent weight gain of $15 \mathrm{lb}$. A re-staging CT scan of the abdomen showed no evidence of polyp recurrence.

\section{Discussion}

The etiology of heterotopic pancreatic and gastric tissue remains incompletely understood; however, both are believed to be congenital. Abnormalities during embryonic development, such as rotation of the foregut and fusion of the dorsal and ventral pancreatic buds, are the likely culprits, although a metaplastic process has also been implicated $[1,2]$.

Heterotopic, pancreatic and gastric tissues are more often found in the upper gastrointestinal tract and organs than in the lower intestinal segments, including the hepatobiliary tree [2]. When symptomatic, patients complain of abdominal pain, weight loss, nausea and vomiting, with or without gastrointestinal bleeding [2, 8]. However, previous reports suggest that two-thirds of isolated ileal pancreatic heterotopia cases are detected incidentally at the time of surgery [9]. When heterotopic tissue causes intestinal inflammation or injury secondary to acid secretion, pancreatic enzymogen activation and tissue digestion, patients will present with corresponding symptoms, sometimes in the urgent setting [10]. Obstruction, intussusception and malignant transformation are also associated findings $[2$, $9,10]$. 
Jiang et al.: Pancreatic and Gastric Heterotopia with Associated Submucosal Lipoma Presenting as a $7-\mathrm{cm}$ Obstructive Tumor of the Ileum

Previous authors have described cases of heterotopic pancreas presenting as a lead point for intussusception in adults $[8,11]$. However, the mass in our case also contained both ectopic gastric and pancreatic tissue, which has only previously been reported in an infant as a cause for ileocolic intussusception [3]. While the combination of pancreatic and gastric heterotopic tissue is a known finding in Meckel's diverticulum, the presence of a submucosal lipoma component in a polypoid mass makes this case unique.

The classic endoscopic findings of heterotopic pancreatic tissue include a protruding, well-demarcated mucosal and/or submucosal lesion, occasionally with central umbilication, which represents the orifice of the ductal system, if present. On contrast-enhanced CT, the appearance of heterotopic pancreas mimics the density and enhancement characteristics of normal pancreas proper and often presents as ectopic nodular foci. This case is unique from a radiological perspective because of the close correlation between CT, gross specimen and histological images. The round heterotopic pancreas nodule was surrounded by fat and clearly visualized on both CT (fig. 1) and pathological section (fig. 2).

Rarely, inflammatory conditions and even neoplastic processes originating from the heterotopias can be detected by routine microscopic examination [12]. Imaging studies and endoscopic visualization are neither specific nor sensitive enough to determine heterotopias, and histopathological examination remains the gold standard for identifying such a process. In our case, the lesion was only identified when the patient was systemically evaluated for early rectal adenocarcinoma, which led to a CT of the abdomen and pelvis demonstrating the distal small bowel lesion. The carefully acquired history revealed episodic crampy abdominal pain, nausea and vomiting suggestive of intermittent bowel obstruction. Incorporation of clinical and radiological evaluation ultimately led to endoscopic resection of the mass and a definitive histopathological diagnosis.

Until recently, surgical resection was the only therapeutic option to remove distal small bowel lesions and to obtain the essential histology for diagnosis $[2,10,13,14]$. While small intestinal pancreatic and gastric heterotopias typically have a benign course, neoplasms including adenocarcinomas and carcinoids arising from heterotopic tissue have been reported $[10,15]$. With advancements in deep small bowel enteroscopy, biopsy and endoscopic resection of small bowel lesions that were previously removed surgically due to lack of endoscopic access is becoming more commonplace. As experience in deep small bowel enteroscopy improves, endoscopic management of advanced distal small bowel lesions will begin to mirror the management of similar colonic lesions. In this case, despite the large size of the lesion $(7.5 \times 2.5 \mathrm{~cm})$, which would even prove challenging to remove in more accessible areas such as the colon or stomach, the lesion was safely removed endoscopically without complication. Moreover, the patient's symptoms related to intermittent intussusception were alleviated by endoscopic resection of the lead point lesion. Hence, this case suggests that endoscopic resection may be a reasonable, safe and less invasive alternative for removal of some large small bowel polypoid lesions. 
Jiang et al.: Pancreatic and Gastric Heterotopia with Associated Submucosal Lipoma Presenting as a $7-\mathrm{cm}$ Obstructive Tumor of the Ileum

\section{References}

1 De Castro Barbosa JJ, Dockerty MB, Waugh JM: Pancreatic heterotopia; review of the literature and report of 41 authenticated surgical cases, of which 25 were clinically significant. Surg Gynecol Obstet 1946;82: 527-542.

2 Biswas A, Husain EA, Feakins RM, Abraham AT: Heterotopic pancreas mimicking cholangiocarcinoma. Case report and literature review. JOP 2007;8:28-34.

-3 Al-Zahem A, Arbuckle S, Cohen R: Combined ileal heterotopic pancreatic and gastric tissues causing ileocolic intussusception in an infant. Pediatr Surg Int 2006;22:297-299.

-4 Shehata B, Chang T, Greene C, Steelman C, McHugh M, Zarroug A, Ricketts R: Gastric heterotopia with extensive involvement of the small intestine associated with congenital short bowel syndrome and intestinal malrotation. Fetal Pediatr Pathol 2011;30:60-63.

5 Lai EC, Tompkins RK: Heterotopic pancreas. Review of a 26 year experience. Am J Surg 1986;151:697-700.

6 Scholz S, Loff S, Wirth H: Double ileoileal intussusception caused by a giant polypoid mass of heterotopic pancreas in a child. Eur J Pediatr 2000;159:861-862.

7 Gurbulak B, Kabul E, Dural C, Citlak G, Yanar H, Gulluoglu M, Taviloglu K: Heterotopic pancreas as a leading point for small-bowel intussusception in a pregnant woman. JOP 2007;8:584-587.

-8 Chandra N, Campbell S, Gibson M, Reece-Smith H, Mee A: Intussusception caused by a heterotopic pancreas. Case report and literature review. JOP 2004;5:476-479.

-9 Tanaka K, Tsunoda T, Eto T, Yamada M, Tajima Y, Shimogama H, Yamaguchi T, Matsuo S, Izawa K: Diagnosis and management of heterotopic pancreas. Int Surg 1993;78:32-35.

10 Koh HC, Page B, Black C, Brown I, Ballantyne S, Galloway DJ: Ectopic pancreatic-type malignancy presenting in a Meckel's diverticulum: a case report and review of the literature. World J Surg Oncol 2009;7:54.

$\checkmark 11$ Chuang MT, Tsai KB, Ma CJ, Hsieh TJ: Ileoileal intussusception due to ileal ectopic pancreas with abundant fat tissue mimicking lipoma. Am J Surg 2010;200:e25-e27.

$\checkmark 12$ Mehra R, Pujahari AK, Jaiswal SS: Duodenal heterotopic pancreatic tissue: a case report and literature review. Gastroenterol Rep (Oxf) 2014, Epub ahead of print.

13 Ganapathi S, Villa F, Perera R, Wan A: Ectopic pancreas, intussusception, and a ruptured mesenteric band: an unusual association. Clin Anat 2011;24:128-132.

14 Sodhi KS, Fink AM: Education and imaging. Gastrointestinal: Aberrant ileal pancreas causing intussusception. J Gastroenterol Hepatol 2009;24:322.

15 Kusumoto H, Yoshitake H, Mochida K, Kumashiro R, Sano C, Inutsuka S: Adenocarcinoma in Meckel's diverticulum: report of a case and review of 30 cases in the English and Japanese literature. Am J Gastroenterol 1992;87:910-913. 


\begin{tabular}{ll|l} 
Case Reports in & \multicolumn{2}{l}{} \\
\cline { 2 - 3 } Gastroenterology & Case Rep Gastroenterol 2015;9:233-240 & $\begin{array}{l}\text { @ 2015 S. Karger AG, Basel } \\
\text { www.karger.com/crg }\end{array}$ \\
\cline { 2 - 3 } & DOI: 10.1159/000437047 & Jiang et al.: Pancreatic and Gastric Heterotopia with Associated Submucosal Lipoma
\end{tabular}
Presenting as a 7-cm Obstructive Tumor of the Ileum
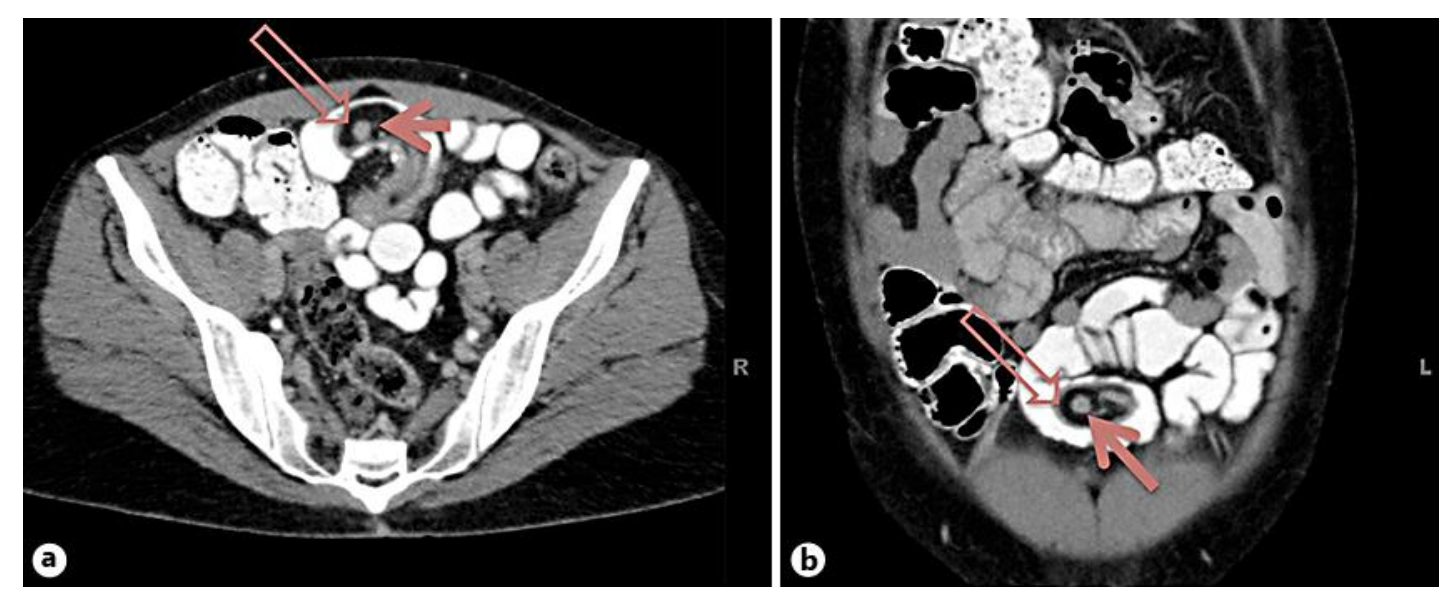

Fig. 1. a Axial contrast-enhanced CT with oral contrast. A polypoid mass with a central round nodule (filled arrow) and surrounding low density fat serves as a lead point for intussusception into a lower anterior loop of ileum. The round nodule correlates with pancreatic tissue on pathology. Soft tissue thickening along the margin of the polypoid mass (open arrow) correlates with the location of gastric tissue on pathology. b Contrast-enhanced coronal reconstruction demonstrates the polypoid nature of the mass which lies completely within a contrast filled loop of ileum. The round pancreatic rest (filled arrow) is surrounded by fat tissue with a mildly thickened rim (open arrow).
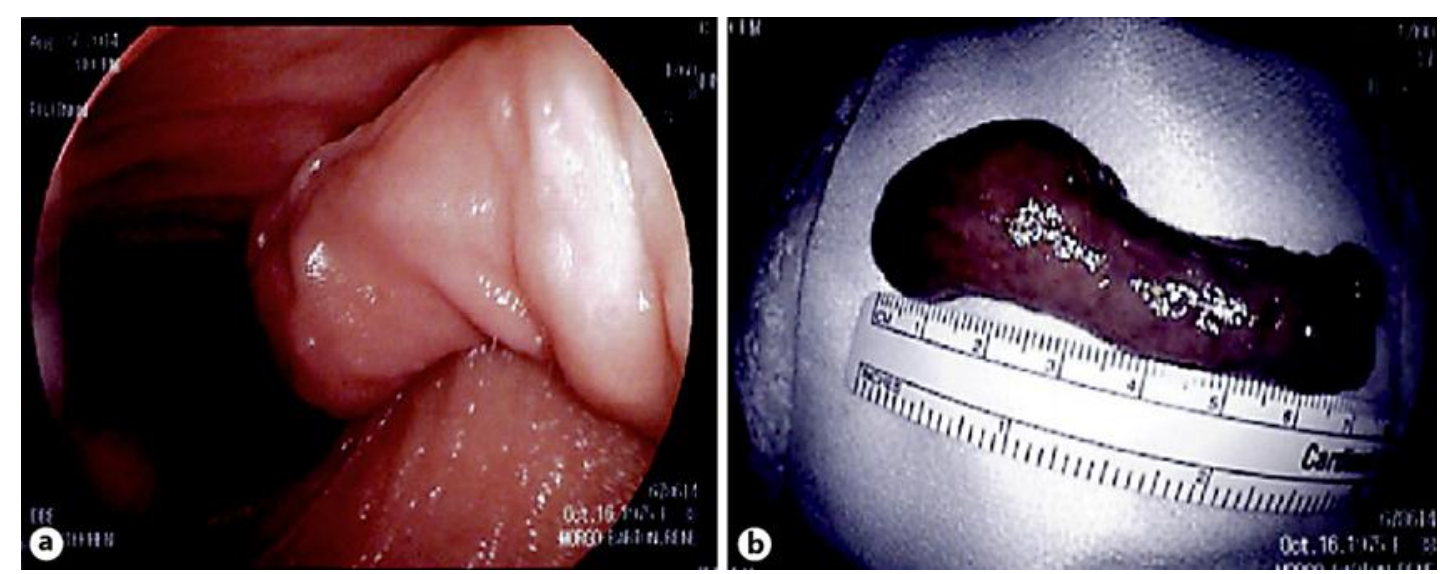

Fig. 2. The terminal ileum mass lesion endoscopically identified (a) and excised, measuring $7 \mathrm{~cm}$ in its greatest dimension (b). 
Jiang et al.: Pancreatic and Gastric Heterotopia with Associated Submucosal Lipoma Presenting as a 7-cm Obstructive Tumor of the Ileum
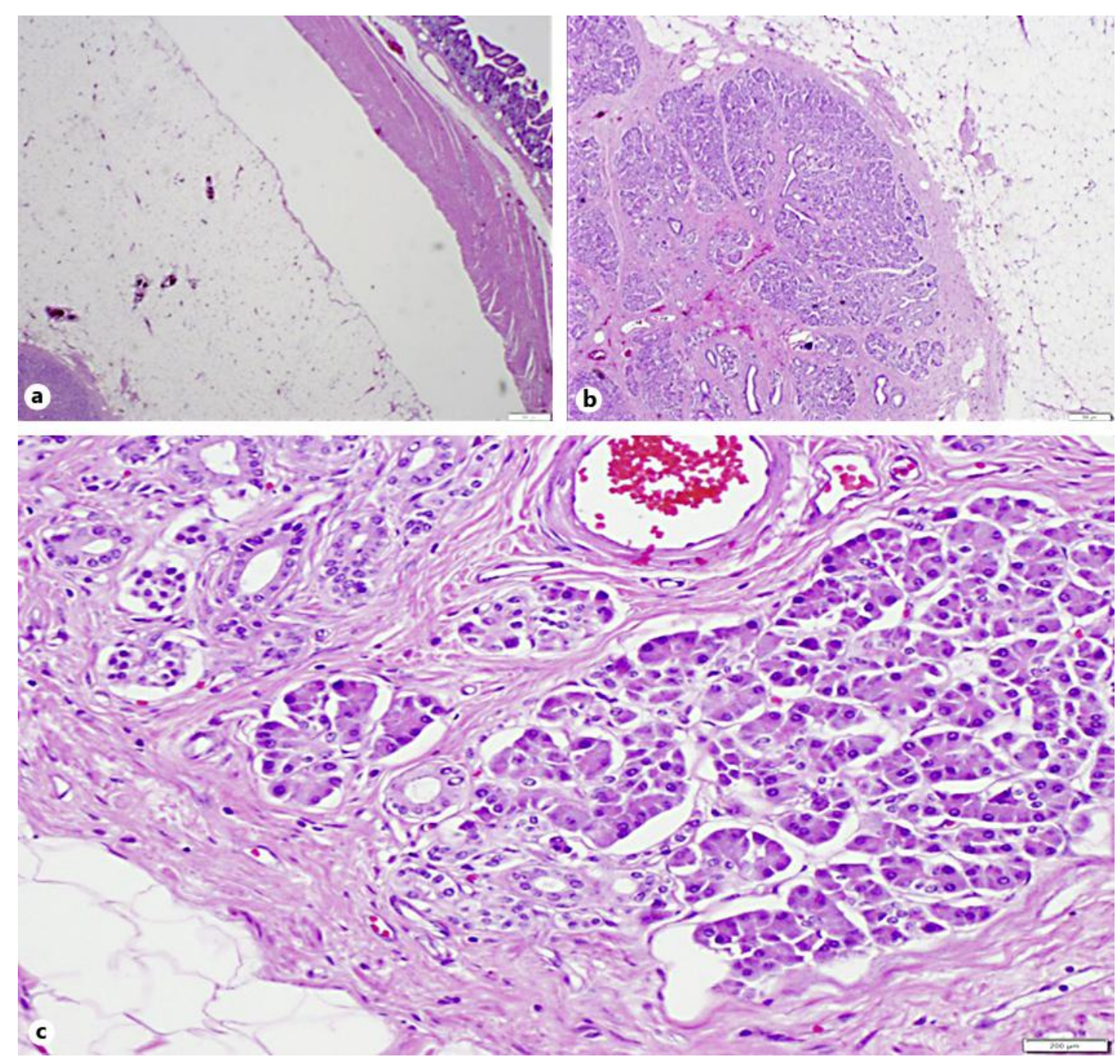

Fig. 3. Histological sections (H\&E) of the terminal ileum 'tumor'. a Low-power $(\times 2)$ cross-section. The submucosal lipoma, the centrally located benign pancreatic tissue and the overlying circular small intestinal mucosa are well illustrated. $\mathbf{b}$, $\mathbf{c}$ Low-power $(\mathbf{b}, \times 4)$ and medium-power $(\mathbf{c}, \times 10)$ H\&E section revealed the presence of pancreatic acini and ducts, surrounded by mature adipose tissue of the lipoma. No dysplasia or atypia is seen. 


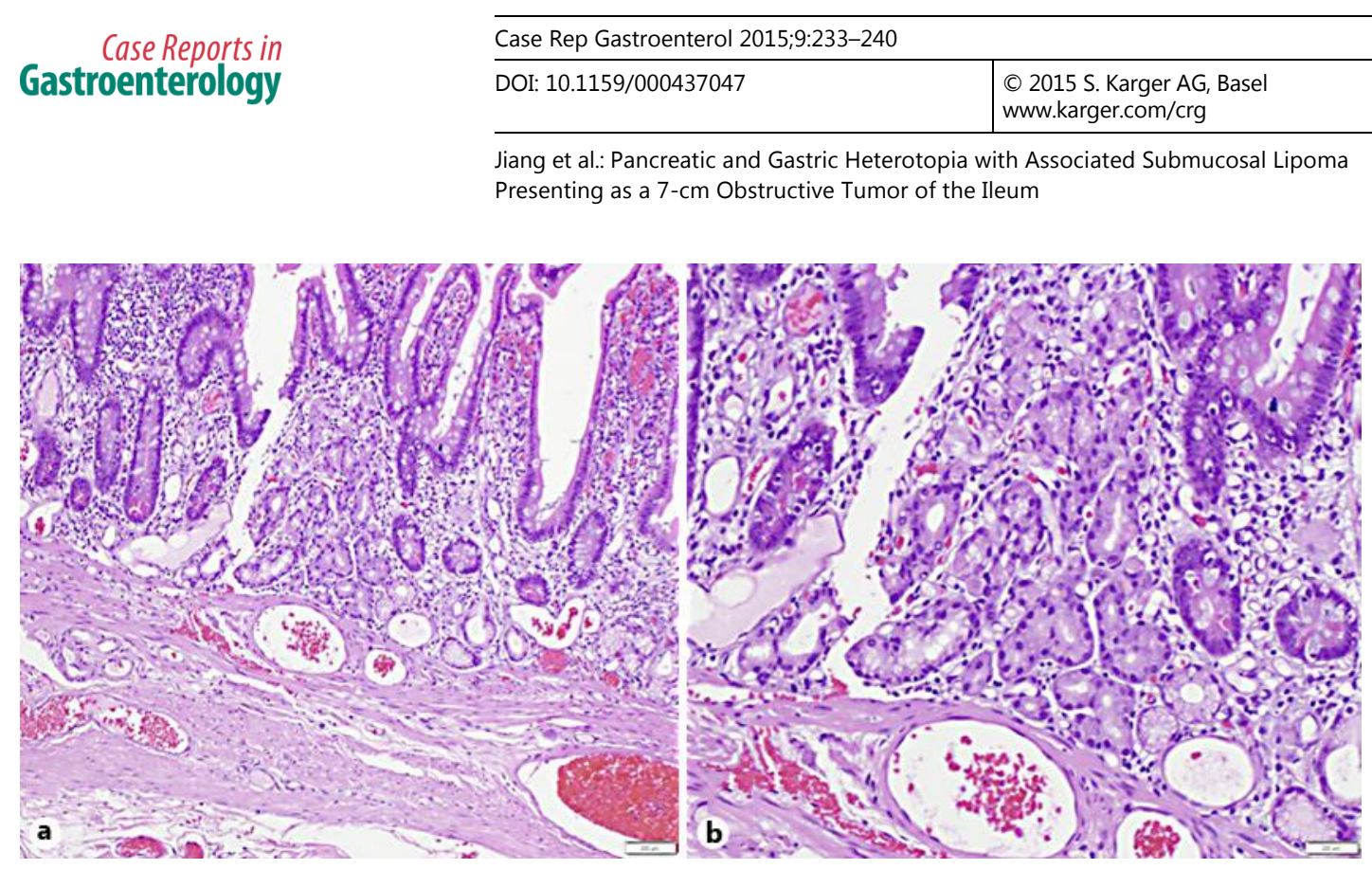

Fig. 4. Histological medium-power (a, 10x) and high-power (b, 20x) H\&E sections revealed the presence of a microscopic focus of oxyntic-type glands and the surface foveolar epithelium adjacent to unremarkable small intestinal mucosa. No dysplasia or atypia is seen. 